\title{
Acerca dos diferentes graus de distinção em fonologia: o caso dos fonemas portugueses em dissílabos do tipo CVCV
}

\author{
Mário Eduardo Viaro* \\ Zwinglio O. Guimarães-Filho*
}

\begin{abstract}
RESUMO: o conceito estruturalista de fonema se define como o menor unidade segmental de uma língua, depreensível por meio de contrastes de pares mínimos. Entretanto, o número de produtos em cada oposição é muito distinto. As diferenças da função distintiva são analisadas nesse artigo a partir do conjunto de todas as palavras portuguesas que tenham a estrutura CVCV encontradas no dicionário Houaiss $\mathrm{O}$ efeito da inclusão de formas flexionadas, bem como de palavras com baixa frequência de uso também é levado em conta. Outras perspectivas de análises são possíveis, além das tradicionais, para a questão da distinção fonológica.
\end{abstract}

Palavras-chave: fonologia; dissílabos; Português; fonema; par mínimo.

\begin{abstract}
Structuralism, is defined as the smallest segmental unit of a language which is apprehensible by means of contrasts of minimum pairs. Nonetheless, the number of products in each opposition is very dissimilar. The differences of the distinguishing function are analyzed in this paper by means of the set of all Portuguese words from the Houaiss dictionary which has the CVCV structure. The effect of the inclusion of inflected forms, as well as of words with a low use frequency is also considered. Other perspectives of analysis are possible for the question of the phonological distinction, beyond the traditional ones.
\end{abstract}

Keywords: Phonology; dissylables; Portuguese; phoneme; minimum pair.

\footnotetext{
Departamento de Letras Clássicas e Vernáculas - Universidade de São Paulo (USP). E-mail: maeviaro@usp.br

** Instituto de Física - Universidade de São Paulo (USP). E-mail: zwinglio@if.usp.br
} 
1. Introdução

1.1. Breve histórico

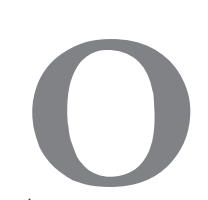

termo fonema surgiu muito tempo depois do termo fonologia, por estranho que isso nos soe hoje. Sob a forma francesa phonème, foi utilizado na linguística pela primeira vez por um certo Dufriche-Desgenettes, inspirado na palavra grega $\phi \omega ́ v \eta \mu \alpha$ "som de voz, fala, discurso". Assim, na ata da reunião do dia 24 de maio de 1873 na Revue critique d'bistoire et de littérature (1873, p. 368), cita-se um trabalho desse autor sobre as vogais nasais: "Nous remarquons dans le mémoire de M. Dufriche-Desgenettes l'emploi de plusieurs termes grammaticaux dont il est l'inventeur: entre elles, le mot phonème, qui est heureusement trouvé pour désigner d'une façon générale les voyelles et les consonnes" [trad. "observamos na ata sobre o emprego de vários termos gramaticais por M. Dufriche-Desgenettes, dos quais é o inventor: entre eles, o termo fonema, que acertamente inventou para designar, de um modo geral, as vogais e as consoantes"]. No Bulletin de la société de linguistique de Paris, do mesmo ano, uma outra ata foi publicada, sobre a mesma reunião (1873, p. 62-63), mas apenas se menciona vagamente o fato "Il est donné lecture d'un travail de M. Dufriche-Desgenettes sur la nature des consonnes nasales" [trad. "deu-se a leitura de um trabalho de M. DufricheDesgenettes sobre a natureza das consoantes nasais"]. Tendo sido adotado por Louis Havet no ano seguinte na revista Romania (1874, p. 321-338), que dá crédito ao colega ("Phonème: terme que j'emprunte à $M$. Dufriche-Desgenettes de la Société de Linguistique de Paris, désigne un son articulé quelconque, voyelle ou consonne", trad.: "fonema: termo que tomo emprestado de M. DufricheDesgenettes, da Sociedade de Linguística de Paris, designa um som articulado qualquer, vogal ou consoante"), o termo passou a ter maior visibilidade. Muitos ainda o empregaram com esse sentido genérico: o próprio FerdinandMongin de Saussure, em 1879, o faz em seu célebre texto Mémoire sur le système primitif des voyelles dans le langues indo-européennes. Mas o grande salto ocorreu quando a Escola de Kazan adotou o termo: o polonês Ian Niecisław Baudouin de Courtenay e sobretudo seu discípulo Mikołaj Habdank Kruszewski serão o ponto de partida para a investigação dos fonemas como unidades mentais. Muitos linguistas partirão dessas ideias - principalmente sob o intermédio de L. V. Ščerba ( Лев ВладимировичЩерба) - durante a criação do IPA na virada do século XX. Apesar de ter uma história longa, o conceito "moderno" de fonema é atribuído ao Círculo de Praga e a seu representante, N. S. Trubetzkoy (Николай Сергеевич Трубецкой), que, após rejeitar a definição psicológica de Courtenay e a sua postulação por meio das variantes de Jones, opta pelo critério da comutação bloomfieldiano, 
de onde se extraem os microfonemas de W. F. Twaddell "Alle Mikrophoneme, die dieselbe Stelle in verschiedenen gleichgeordneten Formklassen einnehmen, bilden ein Makrophonem, das unserem Begriffe Phonem entspriche" (1939, p. 40) [trad.: "todos os microfonemas que tomam a mesma posição em distintas classes formais ordenadas de maneira idêntica, formam um macrofonema, que corresponde ao nosso conceito de fonema"]. O fonema deixa de ser uma unidade física ou psíquica e adquire o valor de uma abstração: Trubetzkoy habilidosamente equivale as unidades "abstractious, fictious unit" twadellianas às "entités oppositives, relatives et négatives" saussurianas, já reconhecidas por outros autores, como de Groot e Sotavalta (TRUBETZKOY, 1939, p. 41).

\subsection{Graus de distinção}

Atendo-se às regras para determinação dos fonemas ditadas por Trubetzkoy, sobretudo à segunda delas "Wenn zwei Laute genau in derselben Lautstellung vorkommen und nicht miteinander vertauscht werden können, obne daß sich dabei die Bedeutung der Wörter verändern oder das Wort unkenntlich werden würde, so sind diese zwei Laute phonetische Realisationen zweier verschiedener Phoneme" (1939, p. 44) [trad.: "se dois sons ocorrerem exatamente na mesma posição e não podem ser confundidos um com o outro, sem que o significado das palavras modifique ou torne a palavra irreconhecível, então esses dois sons serão realizações fonéticas de dois fonemas distintos"], podemos de forma indiscutível aliar o conceito da menor unidade do significante a uma parcela do significado do signo. Essa regra é a mais pacífica de todas e está no cerne de tudo que se discutirá sobre o fonema a partir de então até o surgimento das análises de CHOMSKY \& HALLE (1968). Longe de ser algo ultrapassado, o conceito de fonema preside o ponto de partida de muitas discussões fonológicas atuais, mesmo quando se trata da fonologia nãolinear e da fonologia de usos, de modo que ao tentar superá-lo, sem entender o seu envolvimento com inúmeros fatores para além do que se entende por um sistema linguístico, acabaram por conduzir a esquematizações que fazem sentido apenas nos modelos, mas não na língua per se. Diz-se, por exemplo, que dois sons não pertencerão ao mesmo fonema se, ao comutarmos, um pelo outro, obtivermos palavras de significados distintos. Sabido é que essa comutação não é absoluta: ninguém tem dúvida de que /p/ seja um fonema do português, mas se comutarmos /b/ por /p/ na palavra /bra'ziL/, obteríamos*/pra'ziL/ que, aparentemente, não significaria nada. Mas costumase afirmar que essa palavra existe virtualmente no português, pois respeita, por exemplo, a todas suas regras silábicas e, muito embora não se atribua facilmente a ela qualquer significado. Por outro lado, se um alemão pronuncia, 
conforme seu sotaque, a mesma palavra como [pRa'sil], é fácil reconhecermos aí uma série de neutralizações importantes para o falante nativo, que não estaria, em última análise, respeitando às normas (no sentido coseriano do termo): o eixo sintagmático, ainda assim, nos permite reconhecer a palavra original. A solução da "palavra virtual", contudo, está prevista nos modelos linguísticos, mas foge de um tratamento empírico. Como julgar de fato se uma palavra existe ou não? (VIARO 2005). Contrastando dois fonemas de palavras "realmente existentes", na situação da regra 2 supracitada de Trubetzkoy, poderíamos ainda concluir:

\section{a) Nem toda oposição tem o mesmo grau de distinção.}

Já se observou que o fonema /ð/ em inglês é bastante raro (muito embora apareça em palavras de altíssima frequência: the, that, though etc.), o que dificulta, na maior parte das vezes, a criação de pares mínimos. FERREIRA NETTO (2001, p. 74-75) observa isso com relação à oposição /b/:/v/, do tipo cabo/cavo, que são muito difíceis de serem obtidas. Afirma que "Essa assimetria entre segmentos labiais surdos e segmentos labiais sonoras, na medida em que apenas estes podem ocorrer com diferente gran de sonoridade, tem a sua origem no processo de formação dos próprios segmentos labiais sonoros". Tal fenômeno também foi observado por VIARO \& GUIMARÃES-FILHO (2007). Dessa forma, nossa hipótese é de que há pares de fonemas cuja oposição é mais aproveitada na língua e, por isso, produzem maior número de pares minimos possiveis do que outros. É muito comum, em muitos contextos fônicos, valer-se de palavras pouco conhecidas ou de formas flexionadas na exemplificação de pares mínimos. Embora não seja a situação mais desejável, isso ocorre devido à dificuldade de avaliar o que vem a ser uma "palavra conhecida" ou qual o grau de uso de determinada flexão em detrimento de outra (com certeza, um item lexical como "fala" é muito mais usado que "falal"), mas mecanismos como o site de pesquisas na internet wwn.google.com hoje conseguem responder parcialmente a essas questões. Perante essa dificuldade ainda presente, nosso artigo se pautará por um corpus definido (os verbetes do dicionário Honaiss).

b) O número de fonemas e arquifonemas não é uniforme.

Embora haja grande acordo com relação aos fonemas do português, há ainda, mesmo dentro de um modelo estruturalista, muitas discussões: o português tem doze fonemas vocálicos ou apenas sete (para tal, é necessário admitir um arquifonema $/ \mathrm{N} /$ )? Ou são oito, visto que em Portugal há oposições entre /a/:/ $/$ num contexto muito específico (a saber, na primeira pessoa do plural do presente e do pretérito perfeito do indicativo, nos verbos da primeira conjugação)? Os arquifonemas são apenas /R/, /S/ e /N/ ou podemos computar também um arquifonema /L/? As diferentes reali- 
zações de /E/ e de /O/ são resolvidas com números que inflacionam a quantidade de arquifonemas: $/ \mathrm{pE}_{1}{ }^{\prime} \mathrm{zadO} /$ poderia realizar-se com [e] ou com $[\varepsilon]$, mas não com [i] (pois / $\mathrm{pi}^{\prime} z a d O /$ seria outra palavra), já $/ \mathrm{pE}_{2}^{\prime} \mathrm{di} / \mathrm{se}$ reali-

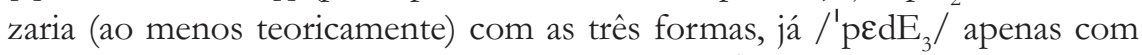

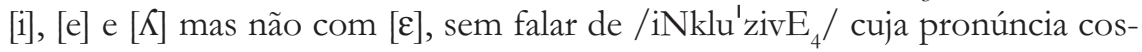
tumeira em Portugal aceita o $[\varepsilon]$ em situação pós-tônica. As mesmas neutralizações poderiam ocorrer em posição tônica: / $3 \mathrm{E}_{5} \mathrm{mE}_{3} / \mathrm{em}$ que o arquifonema neutraliza os fonemas /e/, / $/ \varepsilon /$ e /ẽ/ (a realização com $[\varepsilon]$ é muito comum no oeste paulista, por exemplo), apesar de, dentro de uma tradição estruturalista, não ser uma prática utilizar arquifonemas vocálicos em sílabas tônicas. Essa multiplicação de unidades abstratas é comparável a de outros modelos, hoje considerados questionáveis (como o do modelo saussuriano das duas laringais indo-europeias que se multiplicou a quase uma dezena até se chegar ao "modelo ótimo" de apenas três) e é passível de testes e soluções ad hoc a que qualquer modelo científico se submete até sua total reformulação. Normalmente há uma incompreensível despreocupação com a variação que foge às normas mais populares. Assim, há, no português brasileiro, neutralizações / $\mathrm{v} /: / \mathrm{r} / \mathrm{em}$ amplos territórios (JEROSLOW, 1974), para não citarmos o caso das oposições /s/:/s / nas variantes do norte de Portugal: se tais fatos são levados em conta como fenômenos do sistema da língua portuguesa, o número de arquifonemas aumentaria no primeiro caso e o número de fonemas também cresceria no segundo. Ao mesmo tempo, seria necessário aceitar neutralizações de fonemas na maior parte da lusofonia, com exceção desse pequeno território em que se falam dialetos de pouco prestígio, o que soa um pouco bizarro para nosso modus operandi atual da ciência linguística. Os critérios políticos e o desprestígio das variantes estão, portanto, presentes de forma tácita nos pressupostos do modelo, quando fechamos o número de fonemas e arquifonemas, sem que assumamos essa posição de maneira franca.

\section{c) Alguns fonemas têm posição predefinida.}

Também esse problema já foi levantado quando se discutiu o problema dos fonemas $/ \mathrm{h} / \mathrm{e} / \eta / \mathrm{em}$ inglês: sendo suas posições praticamente excludentes, tratar-se-ia do mesmo fonema? O falante "sente" que não se trata do mesmo fonema e os modelos desenvolvidos ad hoc serviram para respeitar essa "sensação". Em português, não há palavras que comecem com / / / (os casos das realizações sulinas [ $\mathrm{r}$ ] em início absoluto são interpretadas como realizações particulares de um $/ \mathrm{r} /$ inicial) e também são raríssimas as palavras que iniciem com $/ \mathrm{n} /$ e $/ K /$, o que apenas reforça que há posições para os fonemas nas sílabas. Uma sílaba CCCVCCC (interpretação fonética, não fonológica) eventual poderia ser entendida como uma sílaba em português, 
desde que seja o caso em que uma oclusiva na primeira posição do ataque, uma líquida na segunda e uma semivogal na terceira. Igualmente, só pode ter uma semivogal na primeira posição da coda, um arquifonema $/ \mathrm{N} /$ na segunda e um /S/ na terceira, como na última sílaba de /aN.fi.trjojNS/. Fora dessa interpretação não há palavra portuguesa alguma e é sabido que muitas combinações distintas são possíveis nas línguas, como, por exemplo, na primeira sílaba da palavra georgiana / tvramet ${ }^{2} \mathrm{i}$ / "treze" ou no russo / $\mathrm{x} K \mathrm{Kab}$ / "abismo", /'tkatS/ "tecelão" ou /'lz'ets/ "mentiroso".

Impõem-se, portanto, três perguntas associadas às questões acima e tentaremos respondê-las neste artigo.

\section{Oposição vs. Distinção}

Em suma, se um fonema é uma unidade linguística que cria distinções e oposições (melhor dizendo, é distinguivel e oposicionável), esse comportamento não deve ser entendido de maneira absoluta, como normalmente se subentende desde que a visão estruturalista se impôs. As demais correntes, opostas ao estruturalismo, não parecem também ter-se preocupado com isso.

Dados dois fonemas hipotéticos / $\alpha /$ e / / / quaisquer, pertencentes ao mesmo conjunto $\mathrm{S}$ de segmentos de uma língua (sendo que $\mathrm{S}$ equivale ou a $\mathrm{C}$ ou a $\mathrm{V}$ ):

(a) Se um par $/ \alpha /: / \xi /$ define que $\alpha$ e $\xi$ são fonemas, quão produtivo é esse par comparado com um outro qualquer? Ou seja, quão distinguível é este par? Qual é a sua distinguibilidade? Nesse trabalho consideramos que a

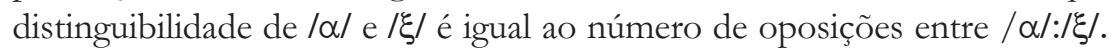

(b) Se um fonema á se opõe aos outros fonemas pertencentes ao conjunto $\mathrm{S}$, quanto ele opõe, comparado com um fonema $\xi$ com relação ao mesmo conjunto S? Ou seja, quão oposicionável é á comparado com $\xi$ ? Qual seria sua oposicionabilidade? Iremos considerar a oposicionabilidade de $\alpha$ igual ao número total de oposições com o fonema $\alpha$.

Dividamos os grupos de fonemas de maneira clássica em vogais e consoantes (incluindo as semivogais no último grupo, mas não consideradas nesta análise). Seja $n$ o número de oposições possíveis entre as vogais. Se temos um número $x$ de fonemas vocálicos, supõe-se que o número máximo de oposições seja igual ao quadrado dessas combinações, excetuando o próprio fonema (obviamente não há sentido numa oposição /a/:/a/). Como o número obtido prevê oposições do tipo /a/:/e/, ao mesmo tempo que /e/:/a/, dividese esse número pela metade. A fórmula final seria $\mathrm{n}=\left(\left(\mathrm{x}^{2}-\mathrm{x}\right) / 2\right)$ ou, de outra 
forma, $n=((\mathrm{x}(\mathrm{x}-1)) / 2)$. Esse seria o número ideal de oposições. Qual é o número real, para cada fonema? Além disso, o número de vezes que cada par ocorre pode ser diferente. Isso nos leva à questão de quão distinguíveis são os pares de fonemas. Uma segunda questão diz respeito a quantas oposições podem ser formadas com cada fonema, ou seja, quão oposicionável é o fonema.

Tendo um corpus definido, o resultado varia ao utilizarem-se formas flexionadas ou não-flexionadas? É sabido que as formas dicionarizadas nominais vêm no masculino e as verbais no infinitivo. Com base em programas feitos na linguagem MatLab, que preveem os casos de irregularidade, defectividade e abundância, assim como as metafonias decorrentes, podemos chegar a resultados muito satisfatórios de simulação de flexão. Uma indagação bastante justa seria se a frequência de uso dessas palavras interfere nesses resultados. A essa indagação buscaremos mais cautelosamente responder em outro momento. Nem sempre o falante nativo, em simulações com palavras descontextualizadas, demonstra ter poder decisivo de reconhecimento perante listas muito extensas, devido a problemas de ordem psicológica, que envolvam a atenção ou a memória. Essa frequência subjetiva nem sempre se revela um bom parâmetro, não obstante esse recurso seja usado pontualmente, em modelos atuais, sobretudos na sintaxe e na morfologia. Fora isso, costuma-se, em larga escala, titubear-se perante nomes próprios e hipocorísticos, onomatopeias, palavras truncadas, flexionadas, assim como perante palavras do universo particular do falante, palavras envolvidas em expressão, palavras incomuns, palavras estrangeiras (cuna, tuna, pindá, finı) e palavras que soam portuguesas (vide, band, chatim, fichu, ganzâa) e palavras deslocadas de seu uso mais comum na flexão (filhô). Outras palavras, nesse teste de reconhecimento, o falante admite já ter ouvido, mas não sabe se as reconhece ou não (godê, japim, panô). Outras não usa, mas sabe que é comum em outros lugares ou por outras pessoas (guri). Outras têm existência justificada em discursos humorísticos (loque, jamé, miguim, sondá, ligá, puxâ). Outras ainda são reconhecidas de maneira acidental (juri). Outras lhes são compreensíveis, mas nunca foram ouvidas antes (sachê). Outras existem, mas não ocorrem no corpus (tajé, żazu, caxi). Enfim, a discussão sobre a existência da palavra é tão difícil quanto a definição de existência em filosofia. Embora seja tema fascinante (e importantíssimo), não cabe sua discussão nesse artigo. Um mecanismo como o Google seria algo que poderia fugir da experiência individual e mostrar, de forma objetiva, se o dado existe ou não em algum discurso, mas dado a heterogeneidade dos textos que comporta, sua triagem se mostra muito complicada também. Não só a questão sobre quantos fonemas há é difícil de se responder, mas os traços que os definem também são sabidamente dependentes dos modelos. Pode-se levar em conta traços do tipo articulatório, os mais antigos 
e objetivos, existentes já nas descrições do século XIX (para o português, veja, por exemplo VIANA 1883) ou traços binários de caráter misto, como os apresentados em CHOMSKY \& HALLE (1968). Neste trabalho, contudo, não trataremos desses elementos infrafonemáticos. No entanto, deve-se relembrar que Trubetzkoy (1939, p. 60-75), em um modelo que envolvia traços articulatórios, propôs vários tipos de oposições. Assim, as oposições monodimensionais (eindimensionale, na tradução francesa bilatérales) se distinguem das polidimensionais (mehrdimensionale, fr. multilatérales) e as oposições isoladas (isolierte) se distinguem das proporcionais (proportionale). As polidimensionais ainda são divididas entre homogêneas (bomogene) e heterogêneas (heterogene) e as homogêneas se subdividem entre lineares (geradlinige) e nãolineares (ungeradlinige). Em todas as línguas, segundo o autor, as mais raras seriam as monodimensionais isoladas, seguidas das proporcionais isoladas, das polidimensionais proporcionais e, por fim, haveria um número muito grande de polidimensionais isoladas. Seriam necessários testes para avaliar a verdade dessa hipótese.

\section{A posição do fonema na sílaba}

A sílaba CV é considerada universal e há muitos motivos para entendêla assim (no caso do português, vide VIARO \& GUIMARÃES-FILHO, 2005). Questões como a posição do fonema na sílaba, no entanto, só podem fazer sentido em uma palavra mínima e a estrutura que analisaremos aqui é o dissílabo $\# \mathrm{C}_{1} \mathrm{~V}_{1} \$ \mathrm{C}_{2} \mathrm{~V}_{2} \#$ ou, simplificadamente, CVCV. Foi analisada uma estrutura silábica CVCV em que os segmentos envolvidos são $V=\{i, u, e, o$, $\varepsilon, \rho, a, \tilde{1}, \tilde{\mathrm{u}}, \tilde{\mathrm{e}}, \tilde{\mathrm{o}}, \tilde{\mathrm{e}}\}$ e $C=\left\{\mathrm{p}, \mathrm{t}, \mathrm{k}, \mathrm{b}, \mathrm{d}, \mathrm{g}, \mathrm{f}, \mathrm{s}, \int, \mathrm{v}, \mathrm{z}, 3, \mathrm{~m}, \mathrm{n}, \mathrm{n} . \mathrm{l}, \Lambda, \mathrm{c}, \mathrm{h}\right\}$. Essa estrutura é ambígua, pois inclui paroxítonas e oxítonas, respectivamente anotadas neste trabalho como 'CVCV e $\mathrm{CV}^{\prime} \mathrm{CV}$. A consoante inicial será sempre referida como $\mathrm{C}_{1}$, a intervocálica como $\mathrm{C}_{2}$, a vogal pretônica como $\mathrm{V}_{1}$, a postônica como $\mathrm{V}_{2}$. A tônica das paroxítonas como ' $\mathrm{V}_{1}$ e a tônica das oxítonas como ' $\mathrm{V}_{2}$. Quando não se leva em conta a tonicidade, indicamos ${ }^{0} \mathrm{~V}_{1}$ ou ${ }^{0} \mathrm{~V}_{2}$. Como citado acima, sabe-se que numa cadeia de fonemas que compõe uma palavra do sistema português, o fonema / $/$ / não ocorrerá nunca na posição $\# C_{1}$, ao passo que $/ \mathrm{n} / \mathrm{e} / K /$ são extremamente raros na mesma posição. Por definição, em $V_{1} \$ C_{2}$, se $C_{2}$ é uma nasal, $V_{1}$ não o é e, nas mais variadas interpretações dos fonemas. $\mathrm{Se}_{2}$ é uma átona postônica, a distinção dos fonemas vocálicos não-nasais se restringe apenas a /a, i, u/. Esses casos (e outros menos evidentes) serão referidos a seguir como resultados do fenômeno da restrição posicional e acentual. 


\section{Metodologia e corpus}

Por meio de programas feitos na linguagem MatLab desenvolveramse ainda um separador silábico e um transliterador, cujo uso foi explicado em outras publicações (VIARO \& GUIMARÃES-FILHO, 2005). Baseando-se em extensas listas transliteradas de palavras portuguesas, todas abonadas no dicionário Houaiss da língua portuguesa (150.875 palavras lematizadas ou 1.336.965 palavras flexionadas, que formam respectivamente a base lematizada BL e a base flexionada BF), separaram-se todos os CVCV, considerando uma simulação da realização dos fonemas em português brasileiro que incluía epênteses, monotongações de ou, ei e apócope do $-r$ dos infinitivos. Observamos ao manipular os dados, sem que pudéssemos aprofundar-nos, algo que convencionamos chamar de pseudo-oposições. Alguns poucos pares que podem ser estabelecidos automaticamente, seguindo o método exposto, na prática não o são. Contudo, não se trata de neutralizações. A palavra rinhadeiro é sinônima de rinhedeiro, por isso, neste caso a oposição /a/:/e/, em princípio, não se estabelece. Em algumas acepções, tambeiroé o mesmo que tombeiro, ou seja, a oposição /ã/:/õ/ se estabelece parcialmente. $\mathrm{O}$ mesmo ocorre com a oposição por icto (bênção e benção, por exemplo). O elemento semântico das CVCV não foi, contudo, analisado. Supôs-se, portanto, que cada elemento era único, tanto do ponto de vista do significante quanto do significado, da mesma forma que todos os elementos homófonos foram descartados. Com referência à BL, havia 1653 casos de homófonos, todos heterógrafos. Desses, 1605 tinham transcrições distintas (e desses, 1564 tinha um homófono; 34 tinham dois e 7 tinham três). Extraindo esses casos, temos uma BL "limpa" de 149.222 sequências sonoras distintas. Igualmente, com referência à $\mathrm{BF}$, havia 288.744 casos de homofonia, não necessariamente de heterografia (a flexão verbal automática gerava vários casos de homógrafos). Desses, 235.110 dispunham de transcrições distintas (ou seja, 213.150 tinha um homófono; 5.410 tinham dois; 2064 tinham três; 14.290 tinham quatro; 74 tinham cinco; 15 tinham seis; 5 tinham sete; 1 tinha oito; 99 tinham nove e 2 tinham catorze). Extraindo esses casos, temos uma BF limpa de 1.048.221 sequências sonoras distintas. Um verbo gerava homófonos homógrafos em várias situações: pretérito imperfeito do indicativo, na primeira e terceira pessoas do singular; terceira do plural do pretérito perfeito e mais-que-perfeito do indicativo; primeira e terceira pessoas do singular do infinitivo flexionado, infinitivo não-flexionado e primeiras e terceiras pessoas do futuro do subjuntivo dos verbos regulares etc. Isso explica a desproporção entre palavras com oito e nove homófonos. 
Uma semelhante pesquisa com palavras "reais", isto é, retiradas de corpora falados, poderiam refletir (ou não) resultados, semelhantes. No entanto, o motivo pela nossa opção por palavras transcritas a partir de um extenso corpus escrito, sem a inclusão de fatores estilísticos de difícil mensuração (como, por exemplo, se a palavra é usual) se deve a uma tentativa de abarcar o problema como um todo. Esta análise, salvo melhor juízo, é um primeiro passo para verificarem-se questões pouco discutidas ou sequer aventadas, como a da relatividade da noção de "oposição fonológica". Ressente-se, no nível indutivo, de uma tipologia estilística realmente científica, a partir da qual se possam incluir variantes ao modelo proposto, de modo que as afirmações aqui desenvolvidas não se revelem parciais ou talvez presas de forma ineficaz a um corpus, sem refletir a noção de sistema, a qual, embora abandonada (justamente, diga-se de passagem) por alguns modelos dedutivos que privilegiem o fato linguístico, se trata ainda da abstração mais importante (da mesma forma que, por exemplo, o conceito de animal o é para a zoologia) e, por conseguinte, ponto de partida para desejáveis sínteses científicas de modelos apenas aparentemente antagônicos,

Observe-se que considerar as palavras flexionadas (BF) tornou o número total de CVCV sem homófonas apenas 1,56 vezes maior (de 3733 para 5841) enquanto no total do número de verbetes sem homófonas o aumento relativo foi muito maior: 7,02 vezes (de 149222 para 1048 221). Outro dado que se pode observar na Tabela 1 é que o número de oposições na BF é 2,11 vezes maior que na BL (44 918 e 21289 verbetes, respectivamente). Ou seja, o aumento de $56 \%$ no número de CVCV não homófonas resultante da consideração das formas flexionadas levou ao aumento de $111 \%$ no número de oposições encontradas.

Dadas as condições máximas, o número de palavras CVCV virtualmente possíveis não-homófonas seria 19x12x19x12 = 51.984. Sendo que existem palavras oxítonas e paroxítonas, o número dobraria (103.968). O número real, no entanto, é bem menor (ou seja, 5841, ou seja, apenas 5,62\% das palavras virtuais). Esse número, por ser pequeno, é bastante curioso, ainda mais quando estamos falando de um corpus carregado de palavras desusadas (por terem 
Tabela 1: quantidade de palavras do corpus

\begin{tabular}{|c|c|c|c|c|}
\hline \multirow[t]{4}{*}{$\begin{array}{l}\text { Lematizadas } \\
\text { (BL) }\end{array}$} & & $\begin{array}{l}\text { Todas das } \\
\text { CVCV }\end{array}$ & Homófonas & $\begin{array}{l}\text { Total de CVCV } \\
\text { sem homófonas }\end{array}$ \\
\hline & $\begin{array}{l}\text { número de palavras do } \\
\text { tipo CVCV }\end{array}$ & 3978 & 245 & 3733 \\
\hline & número de oposições & 24925 & 3636 & 21289 \\
\hline & $\begin{array}{l}\text { Número de oposições } \\
\text { por icto }\end{array}$ & 530 & 43 & 487 \\
\hline \multirow[t]{4}{*}{$\begin{array}{l}\text { Flexionadas } \\
(\mathrm{BF})\end{array}$} & & $\begin{array}{l}\text { Todas as } \\
\text { CVCV }\end{array}$ & Homófonas & $\begin{array}{l}\text { Total de CVCV } \\
\text { sem homófonas }\end{array}$ \\
\hline & $\begin{array}{l}\text { número de palavras } \\
\text { CVCV }\end{array}$ & 11208 & 5367 & 5841 \\
\hline & número de oposições & 23272 & 168354 & 44918 \\
\hline & $\begin{array}{l}\text { número de oposições } \\
\text { por icto }\end{array}$ & 2140 & 1327 & 813 \\
\hline
\end{tabular}

sido extraídas de dicionários). Se se levasse em conta a frequência de uso, ele seria ainda menor. Apenas para se ter uma ideia, cerca de 10\% dos 150.875 verbetes lematizados não tem nenhuma ocorrência no site de buscas mmm:google.com para buscas restritas à páginas em português (ARAÚJO et al., 2006). Parcialmente, essa restrição pode ser explicada por razões estruturais: $\mathrm{o}$ acento restringe o número de vogais nas átonas, as vogais $\mathrm{V}_{1}$ nasalizadas são excluídas antes de $\mathrm{C}_{2}$ nasais, vibrantes e nasais (exceto pela rara $/ \mathrm{r} /$ ), há restrições para $C_{1}$ que raramente é ocupada por $/ \mathrm{n} /$ e $/ K /$ e nunca por $/ \mathrm{r} /$ etc. Trata-se da restrição posicional.

Mas esta explicação não basta. $\mathrm{O}$ principal motivo para o pequeno número de palavras reais é histórico. Uma forma como */'kuta/ seria virtualmente existente na língua portuguesa. Contudo, não existe no nosso corpus, que contém um número bastante significativo de palavras. Não há nenhuma razão fonológica para sua inexistência. Não há restrições posicionais e a escolha dessas consoantes nessas posições indica, como veremos abaixo, que possui situações ótimas de produção. Obviamente, a existência de uma forma depende, portanto, não apenas do corpus, de fatores fônicos e históricos, mas há ainda variados fatores psicológicos e sociais que interferem nessa decisão (VIARO, 2005): poderíamos afirmar com segurança, tomando o português como base, que */'kuta/ não existe na langue, embora uma análise acústica possa provar que ['kuta], de fato, exista às vezes na parole: nesses casos, sua existência normalmente é justificada à pronúncia rápida e casual da palavra "culta", numa pronúncia infantil (ou, de alguma forma, tida como "individual") da palavra "curta", por exemplo. Essa abordagem, contudo, infelizmente escapa dos objetivos deste artigo. Na prática, estes dados indicam que a língua prefere inflacionar semanticamente uma palavra ao criar um neologismo. O significante 
é particularmente conservador perante o significado, como já percebido pela linguística histórica. A criação de um novo fonema é, portanto, praticamente um capricho da língua. Perante o pequeno número de oposições que encontramos em nossos dados, há até razões para duvidar da existência real de fonemas recentes como $/ K / \mathrm{e} / \mathrm{n} /$ por serem raros e suscetíveis a restrições de ordem contextual, como veremos. No entanto, se são raros, do ponto de vista absoluto, por outro lado, merecem ser computados entre os fonemas, pois pertencem ao mesmo padrão dos fonemas mais antigos na relação entre o número de sílabas de que participam e o número de oposições.

Além disso, é possivel que dadas duas sequências, haja equivalência de todos os segmentos, com exceção do icto. Apesar de não se tratar de uma oposição de tipo fonemático, é importante indicar aqui os dados. Na BL são 487 casos e na BF são 813. Em todos esses casos há algumas restrições: $V_{2}$ são necessariamente /a/, /i/ ou /u/. Na BF também ocorre / ̃̃/, por ex. porem: porém/'porẽe/:/po'rẽe/, contem: contém /'kõtẽ/: /kõ'tẽ/ e outros casos de pseudooposição.

\section{Distinguibilidade}

Se levarmos em conta todo o conjunto de oposições do corpus, encontraremos outros dados. As oposições vocálicas são, de longe, mais profícuas que as consonantais. Essa característica está associada a outro conceito, o de distinguibilidade dos pares (e não dos fonemas vistos absolutamente). Se nos pautamos nas consoantes, teremos o resultado mostrado na figura 1. Observe que as cores quentes (tirantes ao vermelho) referem-se a uma alta distinguibilidade, ao passo que as cores frias (tirantes a azul) apontam para baixa distinguibilidade. Além disso, atente para o fato de que a diagonal que se forma, com nenhuma distinguibilidade, equivale à impossível oposição de um determinado fonema por ele mes-mo (ou seja, do tipo /a/:/a/). A figura 2 é obtida quando distinguimos $C_{1}$ e $C_{2}$. 


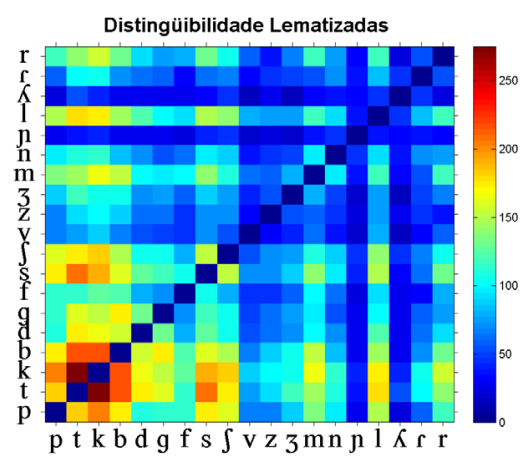

Figura 1 - Distinguibilidade das consoantes na Base Lematizada
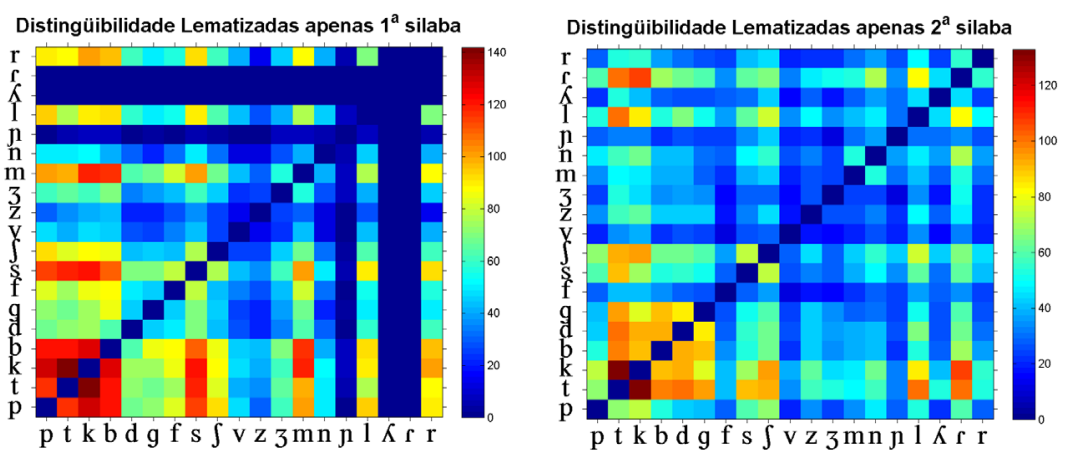

Figura 2 - Distinguibilidade das consoantes na BL para a $1^{\text {a }}$ e $2^{\text {a }}$ sílabas

No caso das vogais teríamos, para todas as vogais novamente um gráfico geral muito concentrado (ver figura 3). A separação entre tônicas e átonas revela um aumento de variação nas tônicas e uma concentração ainda maior nas átonas (ver figura 4). Separando as vogais tônicas ' $\mathrm{V}_{1} \mathrm{e}{ }^{\prime} \mathrm{V}_{2}$ e as átonas $\mathrm{V}_{1}$ e $\mathrm{V}_{2}$ obtemos a figura 5 . 
138 VIARO, Mário Eduardo; GUIMARÃES-FILHO, Zwinglio O.

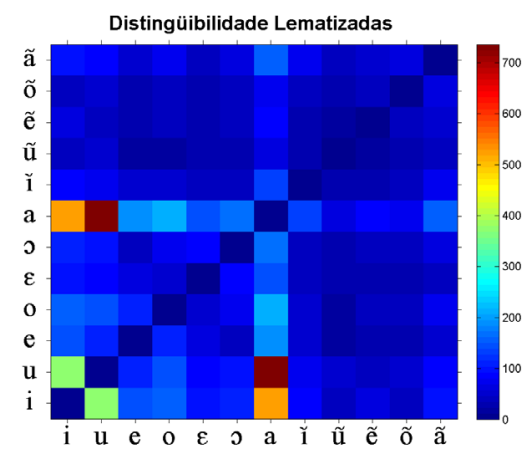

Figura 3 - Distinguibilidade das vogais na Base Lematizada
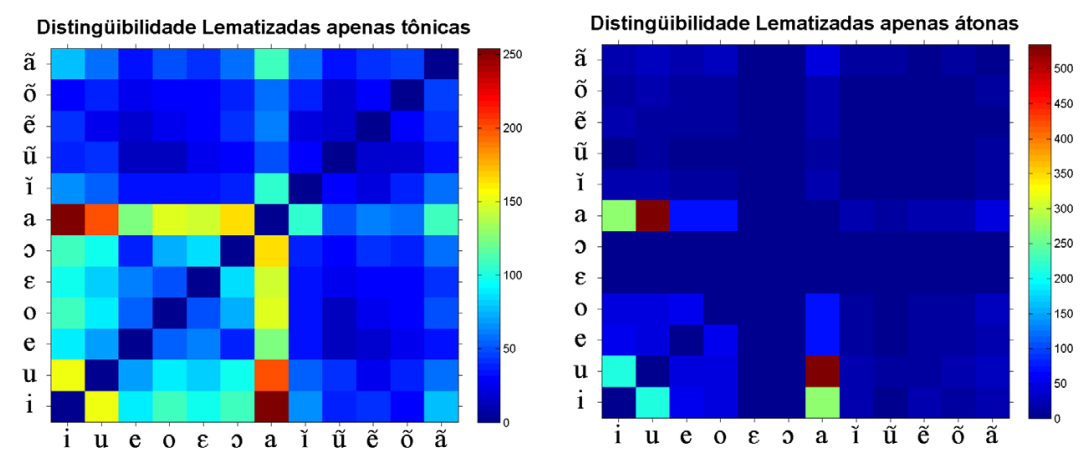

Figura 4 - Distinguibilidade das vogais na BL para as sílabas tônicas e átonas
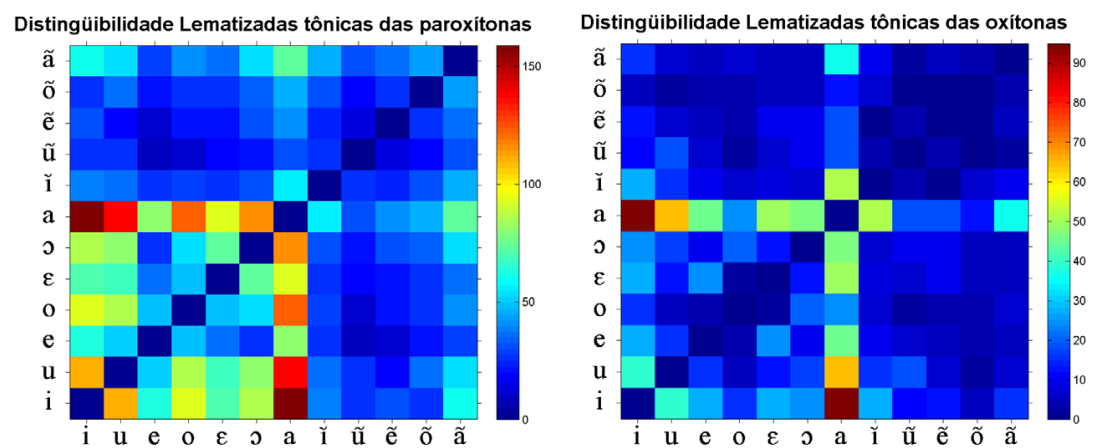


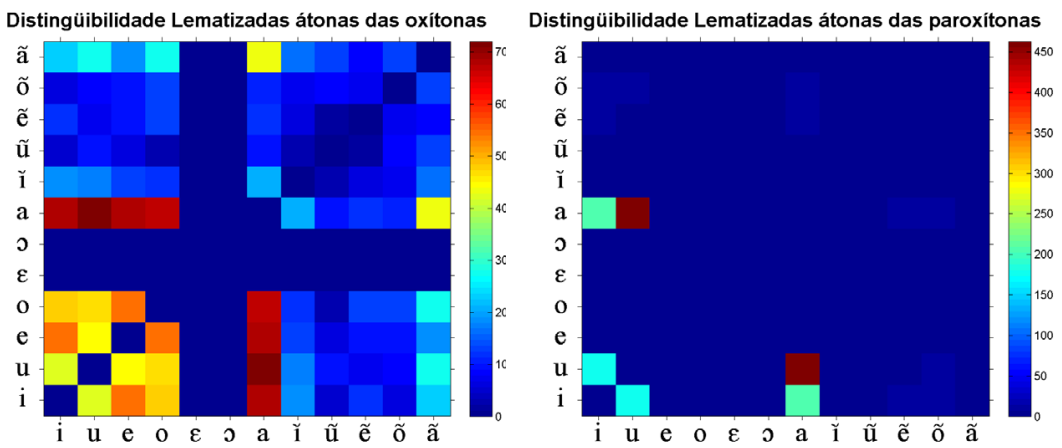

Figura 5 - Distinguibilidade das vogais tônicas e átonas na BL para as paroxítonas e as oxítonas

Surpreendentemente, se aplicarmos a frequência de uso, ou seja, só trabalharmos com as palavras mais usuais do português (selecionadas de acordo com o Google), não há grande diferença, como se poderia esperar, como pode ser visto na figura 6 .
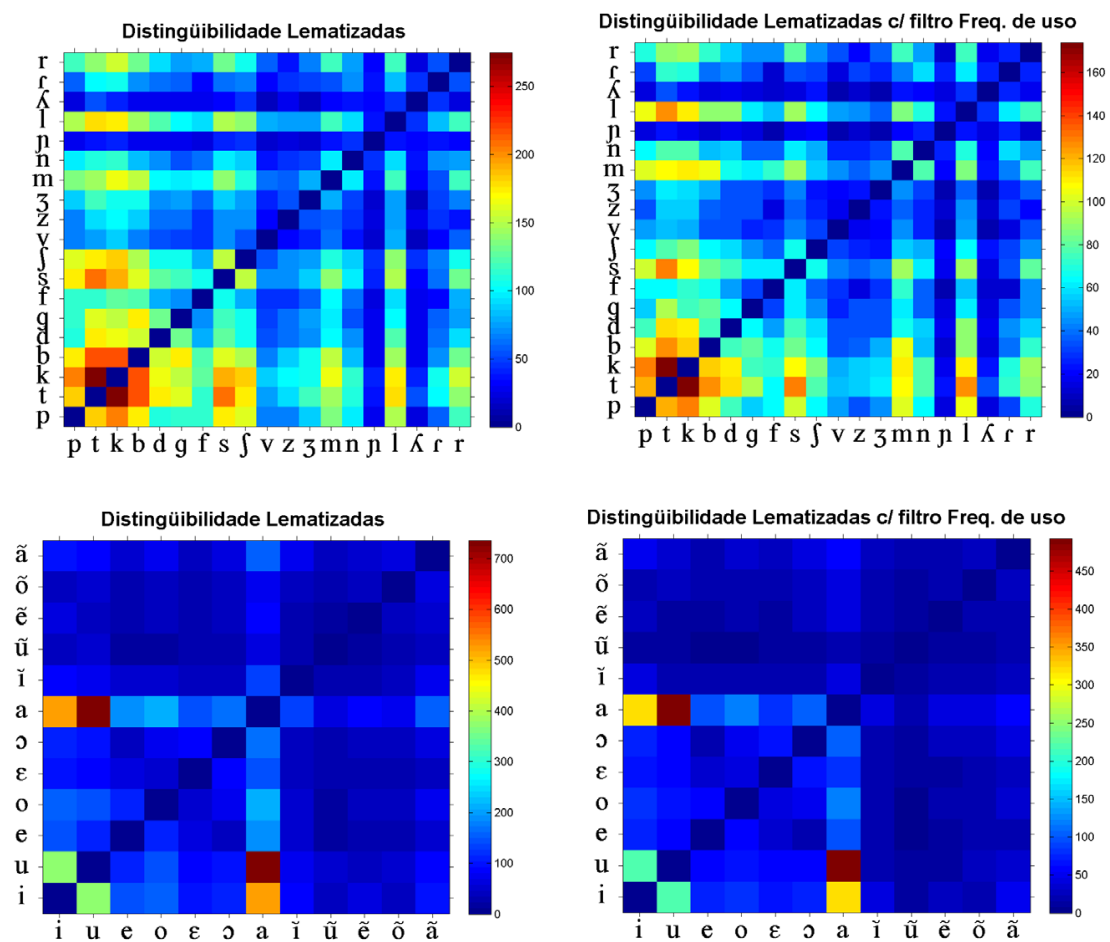

Figura 6 - Efeito do filtro da frequência de uso sobre a distinguibilidade 
De maneira semelhante, o efeito da flexão da base pode ser avaliado, se compararmos lematizadas com flexionadas, obtendo-se a figura 7 .

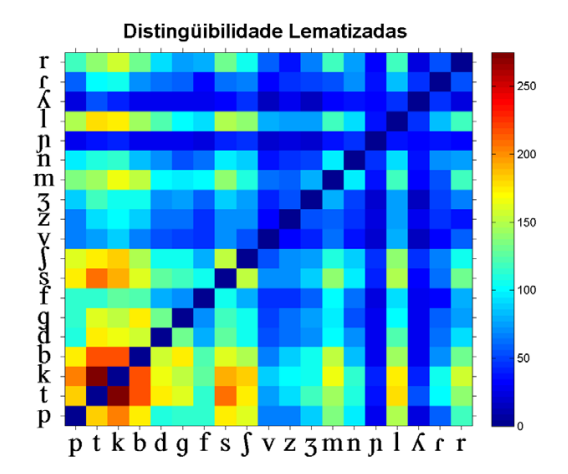

Distingüibilidade Lematizadas

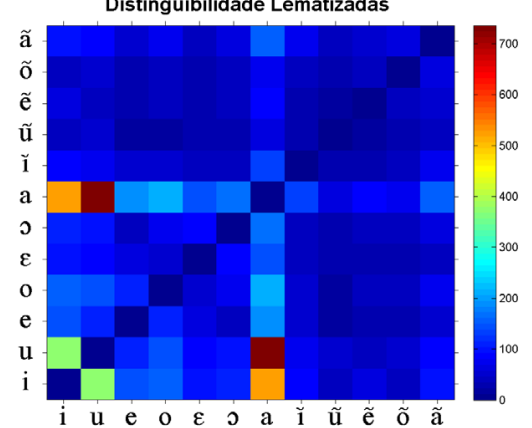

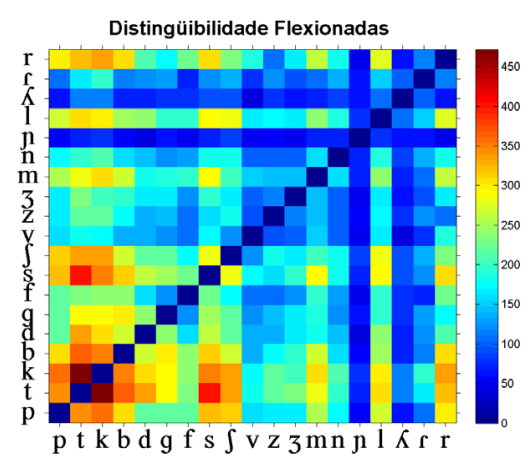

Distingüibilidade Flexionadas

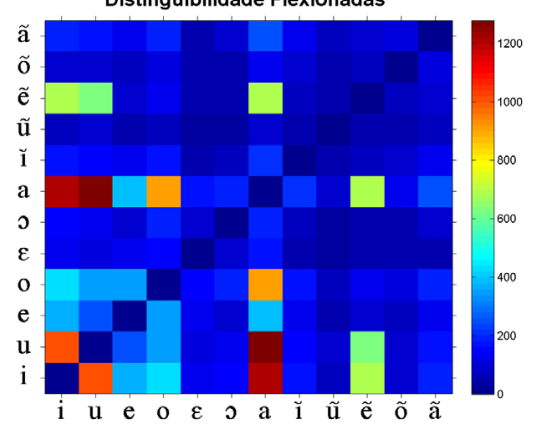

Figura 7 - Efeito da flexão da base sobre a distinguibilidade

Considerando a base flexionada, no caso das vogais, o par mais distinguível seria /a/:/u/ (1279 casos), seguido de /a/:/i/ (1212), /i/:/u/

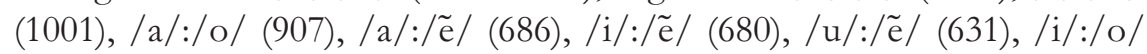
(428) etc. Os pares com menor distinguibilidade seriam /õ $/: / \tilde{\mathrm{u}} /(51), / \mathrm{e} /: /$ $\tilde{\mathrm{u}} /(51), / \varepsilon /: / \tilde{\mathrm{e}} /(49), / \varepsilon /: / \tilde{\mathrm{o}} /(46), / \tilde{\mathrm{e}} /: / \tilde{\mathrm{u}} /$ (40), / $/ \varepsilon /: / \tilde{\mathrm{u}} /(34), / \mathrm{o} /: / \tilde{\mathrm{u}} /$ (33). No caso das consoantes, o par com maior distinguibilidade representa apenas um terço do mais distinguível das vogais: /k/:/t/ (472), /s/:/t/ (405), /b/:/ t/ (365), /k/:/p/ (359), /k/:/s/ (352) etc. Os menos distinguíveis têm, contudo, valores semelhantes aos pares vocálicos menos distinguíveis: $/ \mathrm{r} /: / \mathrm{n} /(50), /$ $\mathrm{f} /: / \mathrm{n} /(46), / \mathrm{d} /: / \mathrm{n} /(44)$ e $/ \mathrm{v} /: / K /(40)$.

Dessa forma, todo fonema consonantal faz 18 tipos distintos de oposições e todo fonema vocálico faz 11, mas há uma grande variação entre a 
quantidade de palavras presentes numa oposição. Apesar de rarissimamente ocupar $\mathrm{C}_{1}$, o fonema $/ K /$, por exemplo, também gera 18 tipos de oposições distintas em $\mathrm{C}_{2}$. A oposição $/ K /: / \mathrm{v} /$, no entanto, ocorre com o menor número de palavras (40) e $/ K /: / \mathrm{t} /$ ocorre com o maior número dentre aquelas que envolvem o $/ K /: 111$ casos. Dizemos, portanto, que $/ K /: / \mathrm{v} /$ é menos distinguível que $/ K /: / \mathrm{t} /$. Comparando esses dados com os de um fonema "antigo" como /t/, o mesmo ocorre (em ambas posições $\mathrm{C}_{1}$ e $\mathrm{C}_{2}$ ). Assim, a oposição mais rara é /t/:/j/ (71) e a mais comum, /t/:/k/ (472). Por exemplo, o par /g/:/b/ (176) opõe mais palavras que o normal de oposições de /g/ e de /b/ (média de 92,2 oposições em pares /g/:C e de 126,5 em pares /b/:C). O mesmo ocorre com /g/:/d/ (130), /n/:/n/ (43), /n/: / / $/(71), / K /: / \mathrm{n} /$ (37), $/ K /: / \mathrm{n} /(31), / \Lambda /: / \mathrm{\Gamma} /(45)$. Em outros pares, a distinguibilidade é menor que o normal como entre $/ \Lambda /: / \mathrm{p} /(23), / \Lambda /: / \mathrm{b} /(29), / \mathrm{n} /: / \mathrm{b} /(28), / \mathrm{n} /: / \mathrm{b} /$ (82), /f/:/f/ (34), /z/: /h/ (36).

\section{Oposicionabilidade}

A noção de oposicionabilidade decorre do conjunto de oposições que um único fonema estabelece na rede de oposições com os demais fonemas. A soma do número total de oposições de que um fonema participa (dentro do conjunto $\mathrm{C}$ ou $\mathrm{V}$ a que pertence, excetuando a si mesmo) define a oposicionabilidade $\omega$ do fonema na base considerada. As oposicionabilidades de cada fonema na BL são mostradas na figura 8. As sequências decrescentes de

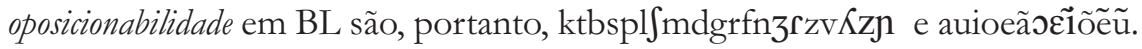

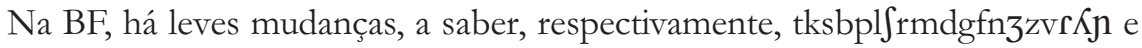

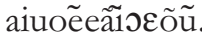

$\mathrm{Na} \mathrm{BF}$, as posições envolvendo o fonema / $K /$ ocorrem, ao todo, num total de 1431 pares de palavras. Diremos, portanto, que a oposicionabilidade de $\Lambda$, ou seja, $\omega(\Lambda)$, é de 1431. Em termos absolutos, o fonema consonantal mais oposicionável (na BF) é /t/ (4875 pares), seguido de /k/ (4826), /s/ (4292), / b/ (4138), /p/ (4005), /l/ (3859), / / / (3826), /r/ (3816), /m/ (3520), /d/ (3447), /g/ (3310), /f/ (2891), /n/ (2631), /3/ (2614), /z/ (2487), /v/ (2261), / $/$ / (2126), / $/ \mathrm{L}$ (1431) e /n/ (1103). Para as vogais, temos: /a/ (5521), /i/ (4500), /u/ (4219), /o/ (3018), /ẽ/ (2592), /e/ (2073), /ã/ (1475), /1/ (1272), /o/ (1142), / / / (1026), /õ/ (899) e ũ/ (641).

É preciso estar atento ao fato de que a diferença entre o número de oposições é, geralmente, muito pequena. Por exemplo, nas vogais /u/ e /i/ da BF temos $\omega(\mathrm{u})_{\mathrm{BF}}=4219$ e $\omega(\mathrm{i})_{\mathrm{BF}}=4500$. Isso implica em uma diferença de 
apenas 281 oposições em cerca de 4500 (ou seja, aprox. 6\% de diferença relativa). Já na BL os números são $\omega(\mathrm{u})_{\mathrm{BL}}=1840$ e $\omega(\mathrm{i})_{\mathrm{BL}}=1742$, diferença de 98 oposições em cerca de 1800 (aproximadamente 5\% de diferença relativa). Isso faz com que a diferença na ordenação (de segunda posição para terceira) não seja muito significativa. O mesmo ocorre com as consoantes. Utilizando o conceito de oposicionabilidade relativa do fonema, $\Omega \rho$, definida como a razão entre o número de oposições envolvendo o fonema e o número total de oposições da base, para que possamos verificar as alterações entre as bases, teríamos, $\Omega \rho(\mathrm{d})$ é igual à $\omega(\mathrm{d})$ dividido pela soma de $\omega(\mathrm{C})$. Com isso, é possível ver que $\Omega \rho(\mathrm{d})_{\mathrm{BF}}=3,6 \%$, ao passo que na BL $\Omega \rho(\mathrm{d})_{\mathrm{BL}}=4,1 \%$. Portanto, $\Omega \rho(\mathrm{d})$ é basicamente a mesma nas duas bases (ver figura 9). Levando o fator frequência de uso em consideração, obtém-se a figura 10.

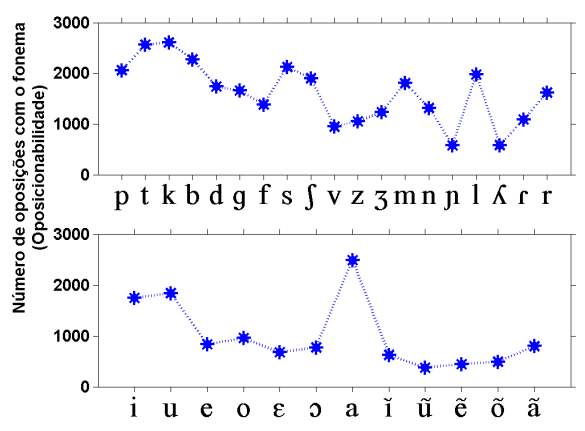

Figura 8 - Oposicionabilidade de consoantes e vogais na Base Lematizada

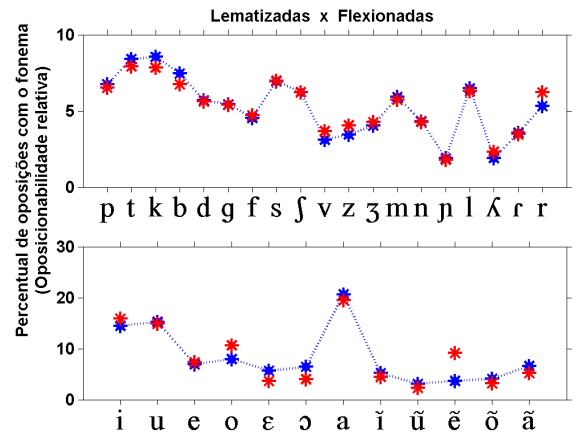

Figura 9 - Efeito da flexão da base sobre a Oposicionabilidade relativa 


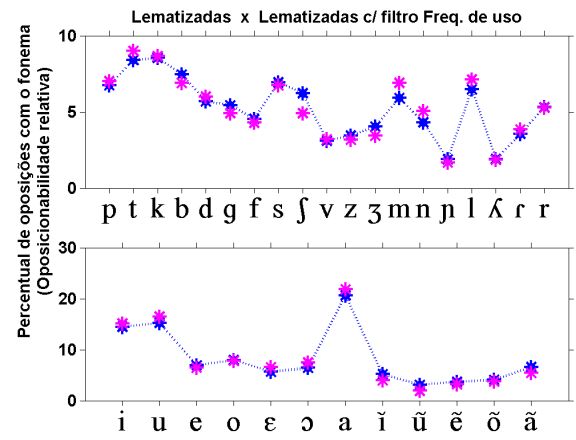

Figura 10 - Efeito do filtro da frequência de uso sobre a Oposicionabilidade

No caso das vogais podemos criar hipóteses acerca de alguns fatores que explicariam por que a sequência: /a/, / i/, /u/ possuem maior oposicionabilidade. Talvez isso ocorra meramente por causa da posição (são as únicas vogais não-nasais em $\mathrm{V}_{2}$ ). A desproporção de /ẽ / face às demais nasais também se dá pela proliferação de $V_{2}$ na BF, quando os verbos são flexionados na terceira pessoa do plural. Nas consoantes, a distorção causada pela flexão praticamente não é perceptível.

\section{Composicionabilidade}

A composicionabilidade de um fonema $/ \alpha /$, ou seja, $\kappa(\alpha)$, é definido aqui como sendo igual ao número de sílabas do corpus que contém o fonema / $\alpha /$. Intuitivamente, é de se esperar que a oposicionabilidade seja proporcional à composicionabilidade (o que matematicamente corresponde à expectativa de que $\omega(\alpha) / \kappa(\alpha)$ seja constante para todo $\alpha)$. Mas os dados mostram que a relação quantitativa entre $\omega(\alpha)$ e $\kappa(\alpha)$ é do tipo $\omega(\alpha)=\mu . \kappa(\alpha)^{\gamma}$, ou seja que a oposicionabilidade é proporcional à composicionabilidade elevada a um expoente $\gamma$ que é significativamente menor do que 1 . Na BF o ajuste aos dados experimentais forneceu os seguintes valores para o expoente $\gamma$ : nas consoantes, $\gamma_{\mathrm{C}}{ }^{\mathrm{BF}}=0,77 \pm 0,04$ e para as vogais $\gamma_{\mathrm{V}}{ }^{\mathrm{BF}}=0,78 \pm 0,03$ (na BL sem filtro por frequência de uso das palavras, os valores obtidos são similares: $\gamma_{\mathrm{C}}{ }^{\mathrm{BL}}=0,78 \pm 0,04$ e $\left.\gamma_{\mathrm{V}}{ }^{\mathrm{BL}}=0,67 \pm 0,03\right)$. Se $\omega$ e $\kappa$ fossem diretamente proporcionais, o expoente g deveria ser compatível de 1, porém, em todos os casos os valores obtidos para $\gamma$ não são estatisticamente compatíveis com 1. 

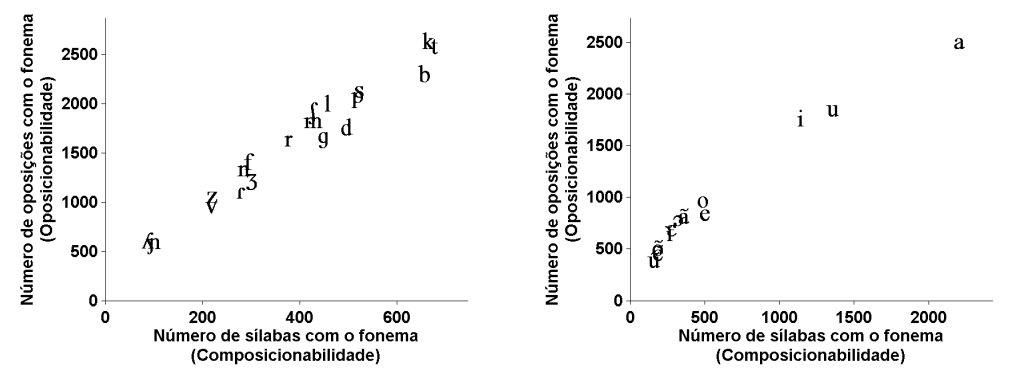

Figura 11 - Relações entre a Oposicionabilidade e a Composicionabilidade na BL

Um ponto importante a ser entendido é a origem do fato do expoente $\gamma$ ser significativamente menor do que 1: se é uma consequência estatística natural (decorrente da probabilidade de combinação de formas com diferentes frequências de ocorrência), ou se é devido à questões linguísticas (que produziriam preferências/rejeições nos acoplamentos entre os fonemas). Para avaliar isso, utilizamos um método conhecido como Simulação Monte Carlo. Assim, fizemos uma simulação de produção randômica de CVCV com dez C e cinco V com composicionabilidades distintas (sem considerar preferências e rejeições) e determinamos o expoente da relação entre $\omega$ e $\kappa$ para estes dados simulados. Obtivemos para estes dados simulados expoentes similares àqueles obtidos na análise dos dados experimentais: $\boldsymbol{\gamma}_{\mathrm{C}}{ }^{\mathrm{S}}=0,80 \pm 0,05 \mathrm{e}$ $\mathrm{g}_{\mathrm{V}}{ }^{\mathrm{S}}=0,71 \pm 0,05$. Isto mostra que o fato de $\gamma$ ser menor que 1 não tem motivação associada à restrições de origem linguística, uma vez que não foram considerados na simulação nenhum tipo de preferência ou rejeição entre os fonemas e mesmo assim os valores dos expoentes obtidos na simulação foram equivalentes aos obtidos na análise dos dados reais.

\section{Preferências e rejeições}

Além das restrições em \#_V, algumas combinações são bastante curiosas e são aqui apenas apresentadas, pois criam inúmeras análises. Definimos como moldes fônicos seis situações envolvendo dois elementos quaisquer de $\mathrm{C}_{1} \mathrm{~V}_{1} \$ \mathrm{C}_{2} \mathrm{~V}_{2}$, a saber: três descontínuos, $\mathrm{C}_{1} \ldots \mathrm{C}_{2},{ }^{0} \mathrm{~V}_{1} \ldots{ }^{0} \mathrm{~V}_{2}, \mathrm{C}_{1} \ldots \mathrm{V}_{2}$ e três contínuos: $\mathrm{C}_{1}^{0} \mathrm{~V}_{1}$, $\mathrm{C}_{2}^{0} \mathrm{~V}_{2},{ }^{0} \mathrm{~V}_{1} \$ \mathrm{C}_{2}$.

a) $\mathrm{C}_{1} \ldots \mathrm{C}_{2}$ : dada uma sequência $\mathrm{CVCV}$ qualquer, há grande número de combinações que envolvam uma oclusiva nas duas sílabas. Quando a $C_{1}$ for / $\mathrm{m} /, / \mathrm{s} /$ ou $/ 1 /, \mathrm{C}_{2}$ tem grande predominância de oclusivas (sobretudo a sequência / $1 . . . d /$ é bastante frequente). No caso de oclusivas em $C_{1}$, há alta 
concentração de / $/, / \mathrm{r} /$ ou $/ \mathrm{l} /$ em $\mathrm{C}_{2}$. É notável observar que sequências como / b...b/ sejam bem mais altas que /p...p/. Em português, oclusivas surdas em $\mathrm{C}_{1}$ "gostam" de oclusivas surdas $\mathrm{em}_{2}$, da mesma forma que oclusivas sonoras em $\mathrm{C}_{1}$ "gostam" de oclusivas sonoras em $\mathrm{C}_{2}$, mas oclusivas sonoras em $C_{1}$ não "gostam" de oclusivas surdas em $C_{1}$ (exceto os casos /b...t/ e / $\mathrm{b} . . . \mathrm{k} /$ ), já oclusivas surdas $\mathrm{em}_{1}$ parecem indiferentes às oclusivas sonoras em $\mathrm{C}_{2}$.

b) ${ }^{0} V_{1} \ldots{ }^{0} V_{2}$ : de longe, a frequência mais alta é /a...a/, seguida de /i...a/ , /u...a/, /a...u/ e /o...a/. Embora /a/ praticamente domine ${ }^{0} \mathrm{~V}_{2}$ neste molde fônico, há também alguns valores significativos para quando ${ }^{0} \mathrm{~V}_{2}$ for $/ \mathrm{u} /$ ou $/$ i/. Quando ${ }^{0} \mathrm{~V}_{1}$ for nasal, é notável observar que há uma rejeição para qualquer ${ }^{0} \mathrm{~V}_{2}$, exceto para quando ${ }^{0} \mathrm{~V}_{2}=/ \mathrm{a} /$.

c) $\mathrm{C}^{0} \mathrm{~V}$ : a escolha de $\mathrm{C}$ pode determinar a escolha de ${ }^{0} \mathrm{~V}$, conforme já se demonstrou com uma amostragem geral que não envolvia simplesmente CVCV, mas todas as estruturas da língua portuguesa (VIARO \& GUIMARÃES FILHO, 2005). Essa preferência ou rejeição pode ser chamada de intrassilábica. Há, contudo uma distinção grande entre $\mathrm{C}_{1}^{0} \mathrm{~V}_{1}$ e $\mathrm{C}_{2}^{0} \mathrm{~V}_{2}$. Chama a atenção o fato de haver frequências altíssimas para /a/ e, um pouco menores, para /u/ no caso $\mathrm{C}_{2}{ }^{0} \mathrm{~V}_{2}$ ao passo que há uma maior distribuição (mas não muito significativa) em $\mathrm{C}_{1}^{0} \mathrm{~V}_{1}$. O fato se dá, como visto, pois ${ }^{0} \mathrm{~V}_{1}$ pode ser uma pretônica ou uma tônica, ao passo que ${ }^{0} \mathrm{~V}_{2}$ pode ser uma tônica ou uma postônica (com visível predileção do último caso, o que faz pensar que há grande número de pares paroxítonos). Um dado curioso aqui apresentado, contudo, é a alta frequência de palavras iniciadas em \#ka, ao passo que o número de palavras terminadas em ta\#, ga\#, ka\#, ba\#, da\#, Sa\#. A desproporção de palavras do tipo \#pi, tu\# também chama a atenção. Por outro lado, za\# é mais comum que \#za.

d) ${ }^{0} \mathrm{~V}_{1} \$ \mathrm{C}_{2}$ : neste molde, há, como visto, algumas restrições posicionais, uma vez que se ${ }^{0} \mathrm{~V}_{1}$ for uma nasal, $\mathrm{C}_{2}$ não poderá sê-lo (nesse caso $\mathrm{C}_{2}$ também não pode ser $/ \mathrm{r} /, / \mathrm{l} /$ ou $/ K /$ embora possa ser $/ \mathrm{r} /$ ). No entanto, há preferências bastante curiosas, como a $\$$ t e $a \$ c$, seguidas de $a \$ k$, a $\$ 1$, i $\$$ k, a $\$ b$. Algumas frequências muito baixas não deixam de ser curiosas, por exemplo, quando ${ }^{0} \mathrm{~V}_{1}$ é nasal e $\mathrm{C}_{2}$ é um $/ \mathrm{v} /$. De modo geral, a frequência só não é desprezível para quando ${ }^{0} \mathrm{~V}_{1}$ for nasal quando se trata de um /ã /.

e) $C_{1} \ldots{ }^{0} V_{2}$.Esta relação é surpreendente, mas não pode deixar de ser considerada. Novamente, o predomínio das paroxítonas terminadas nas únicas vogais possíveis /a/, /u/, /i/ é francamente visível. Alguns moldes são muito curiosos como a alta frequência de \#p...a\#, \#b...a\#, \#s...a\#, \#k...a\#, \#t...a\#, \#m...a\#, \#r...a\#, \#l...a\# e (em escala menor) \#k...u\#, \#b...u\#, \#t...u\#. 
Conclusão

O presente artigo apresenta a relativização de um conceito muito importante nos modelos de linguística, a saber, o conceito de fonema, cujo requestionamento, de modo algum, pode ser pensado como pouco importante, mesmo hoje, após ter havido tantas mudanças pelas quais o conceito passou desde o estruturalismo. É sabido que o conceito de fonema praticamente foi abandonado em uma série de modelos a partir da década de 60 , em favor dos traços, o que deu origem a um conjunto extremamente heterogêneo de discussões, mas o advento de modelos não-lineares de caráter pretendidamente dedutivo não tornou obsoleta a representação intuitiva do fonema nas discussões atuais. Ainda hoje, a representação grafemática dos fonemas pauta-se, em grande parte, em adaptações de símbolos convencionais, sobretudo os do IPA, criados para a fonética e, de modo algum, deixa de entrar entre os pressupostos nas avaliações de fenômenos. Desde muito cedo, tal tendência à distinção entre representação gráfica e o fenômeno em si já se apresentava consubstanciada nos conceitos de broad e narrow transcription. O fonema, desse modo, sempre foi entendido como uma unidade e, desse ponto de partida, nasceu todo o questionamento subsequente dos modelos não-lineares, que em muitos momentos, voltaram-se para representações mais formalizadas das antigas Lautgesetze da linguística histórico-comparativa e privilegiaram elementos intrafonemáticos, como traços, entonação e estruturas. Desse modo, é ainda pertinente o questionamento da base teórica que foi rompida pelos desenvolvimentos posteriores, aliás, esse requestionamento epistemológico é muito salutar quando se pensa em ciência. A oposição promovida pela própria definição de fonema se confundiu - em alguns momentos comprováveis pela historiografia - como uma propriedade intrínseca inalienável de potencialidade plena, embora cedo se tenha percebido haver em algumas oposições certa raridade (mais do que certa abundância de pares, dificilmente obtidos pela intuição).

Por muito tempo, as oposições binárias ditaram todos os padrões do estruturalismo (e mesmo do gerativismo), e na sua base estão pressupostos importantes, como o das ausências significativas nos morfemas-zero ou as formas marcadas em oposição às formas não-marcadas em morfologia. No entanto, um modelo em que se preveja a presença de valências, graus de oposicionabilidade e de distinguibilidade nos fonemas está, no entanto, de certa forma, muito mais próximo do real. Relações de preferência e rejeição apontam para a mobilidade do sistema e elucidam conceitos obscuros e marginais à linguística científica como o de deriva, na linguística histórica, ou de eufonia, na estilística. O próprio eixo sincrônico não se opõe completamente 
ao diacrônico, como hoje se sabe, quando se verificam os valores absolutos, uma vez que oclusivas e a tríade vocálica /a/, /i/, /u/ parecem estar sempre quantitativamente mais bem representados que fricativas ou outras vogais mais recentes.

É sabido que em todas as ciências, os elementos básicos de uma argumentação se fundam não só em dados empíricos, mas também em alguns pressupostos de caráter dedutivo. Quando esses pressupostos são questionados, é preciso reformular muitos conceitos ou até refazer ou mesmo destruir modelos antigos. Pensamos que, frente ao número de dados que manipulamos, é difícil manter argumentos pautados sobre fonemas com potencialidade plena, que fundamentam a base de diversas argumentações teóricas. A relatividade na interpretação das unidades abstratas obtidas na transcrição automática de palavras aponta, todavia, para outras interpretações diferentes das apresentadas neste artigo. Concluímos, portanto, alertando que há muito o que fazer ainda neste campo, até que todas as aparas ao modelo sejam feitas, mas acreditamos que não há outro caminho a trilhar para se fazerem afirmações acertadas sobre a capacidade distintiva dos fonemas.

\section{Referências bibliográficas}

Araújo, G. A.; Guimarães-filho, Z. O.; Oliveira, L.; Viaro, M. E. As proparoxítonas e o sistema acentual do português. In: ARAÚJO, G. A. (org.). O acento em português: abordagens fonológicas. São Paulo: Parábola, 2007, p. 37-60.

Chomsky, N.; Halle, M. The sound pattern of English. Cambridge/ London: MIT, 1968. 470p.

Ferreira Neto, W. Introducão à fonologia da lingua portuguesa. São Paulo: Hedra, 2001. 204p.

Jeroslow, E. H. M. Rural cearense Portuguese: a study of one variety of nonstandard Brazilian speech (Doct. Phil.). Ithaca: Cornell University, 1974. 54p.

Trubetzkoy, N. S. Grundzüge der Phonologie. Praga: Travaux du Cercle Linguistique de Prague (7), 1939. 271p.

Viaro, M. E. Relação entre produtividade e freqüência na produção do significado. Estudos Lingüisticos, Campinas, v. 34, 2005, p. 1230-1235. Disponível em: <http:// www.usp.br/gmhp/ publ/Via29.pdf > . Acesso em 25 set. 2008.

Viaro, M. E.; Guimarães Filho, Z. O. Análise quantitativa da freqüência dos fonemas e estruturas silábicas portuguesas. Estudos Lingüísticos, Araraquara, v. 36, 2007. p. 28-36. Disponível em: <http:// www.usp.br/gmhp/publ/Via32.pdf> $>$. Acesso em 25 set. 2008.

Vianna, A. R. G. Essai de phonétique et de phonologie de la langue portugaise d'après le dialecte actuel de Lisbonne. Romania, Paris, v. 12, 1883. p. 29-98. 